\title{
Sazonalidade de Nyssodrysina lignaria (Bates) (Coleoptera, Cerambycidae, Lamiinae), no Estado do Paraná, Brasil ${ }^{1}$
}

\author{
Renato C. Marinoni ${ }^{2,3} \&$ Norma G. Ganho ${ }^{2,4}$
}

${ }^{1}$ Contribuição número 1412 do Departamento de Zoologia, Universidade Federal do Paraná. Financiamentos da FINEP.

${ }^{2}$ Departamento de Zoologia, Universidade Federal do Paraná. Caixa Postal 19020, 81531-980 Curitiba, Paraná, Brasil.

${ }^{3}$ Bolsista do CNPq. E-mail: rcmari@bio.ufpr.br

${ }^{4}$ Bolsista da CAPES. E-mail: jomario@uol.com.br

\begin{abstract}
Seasonality of Nyssodrysina lignaria (Bates) (Coleoptera, Cerambycidae, Lamiinae), in the Paraná State, Brazil. As part of two surveys in the state of Paraná, Nyssodrysina lignaria (Bates, 1864) (Cerambycidae, Coleoptera) was sampled using malaise traps. One of the surveys was developed in eight different sites (Antonina, São José dos Pinhais, Colombo, Ponta Grossa, Telêmaco Borba, Jundiaí do Sul, Guarapuava e Fênix) from August 1986 to July 1987 and another one in five areas in different conditions of forest conservation, all located at Vila Velha, Ponta Grossa, from September 1999 to August 2000. The data indicate that the seasonality is congruent with the conditions found in temperate regions, with an activity peak in the spring-summer months. In the beginning of fall a second peak of abundance was observed, but not as high as in the spring-summer. These two peaks probably indicate the presence of two populations of $N$. lignaria associated to different fruit-ripening phases on diverse species of Inga Ph.Miller (Leguminosae, Mimosacea). The populational fluctuation observed in the various sites and the temperature and air humidity influences are discussed. Differences in the floristic conditions in Vila Velha (Ponta Grossa), as a cause of punctual differences in the populational fluctuation are also discussed. Finally, the results are compared with a study made with N. lignaria in Santa Maria, Rio Grande do Sul, Brazil.
\end{abstract}

KEY WORDS. Abundance, Inga, Leguminosae, malaise trap, populational fluctuation.

Para estudos que envolvam abundância e riqueza de espécies, base para trabalhos de conservação, é muito importante o conhecimento da sazonalidade (Wolda 1988, SAMWAYS 1995), porém estes estudos não têm merecido muita atenção por parte dos ecólogos (Rosenzweig 1995). A sazonalidade da flora e fauna é determinada por condições abióticas, como as variáveis climáticas e as variações de fotoperíodo, principalmente em áreas de maior latitude. Os grupos animais, em razão de suas características comportamentais, principalmente alimentares, reagem de diferentes formas à influência de diferentes fatores ambientais, não só abióticos, como também bióticos. A sazonalidade das plantas é fundamental para a maioria dos herbívoros, principalmente dos que dependem da floração e frutificação.

São poucas as informações sobre a sazonalidade de Cerambycidae, no Brasil. Zajciw (1958) fez um levantamento dos meses de captura das espécies ocorrentes no Rio de Janeiro. O trabalho mais abrangente sobre a sazonalidade em Cerambycidae foi o de Costa \& Link (1988) sobre a espécie Nyssodrysina lignaria (Bates, 1864), que é também objeto deste trabalho.
A sazonalidade desta espécie não é representativa dos Cerambycidae, em razão do comportamento alimentar da larva (carpófago/espermófago), que pode ser considerado de exceção dentro da família (MARINONi et al. 2001, 2002). No entanto, por sua abundância, a espécie possibilitou a análise de alguns aspectos importantes sobre fenologia, considerando-se sua associação à fenologia dos frutos de diferentes espécies vegetais, principalmente de Inga (Mimosacea), onde as larvas se desenvolvem. Da mesma forma, possibilitou uma análise da influência das variáveis meteorológicas sobre os dados de captura em duas localidades (Fênix e Jundiaí do Sul) situadas em uma área de transição climática, localizada sobre o Trópico de Capricórnio, e que é o limite norte da região de marcada influência das geadas, principalmente nos seus pontos de maiores altitudes (MAACK 1981).

O propósito deste trabalho é apresentar e discutir a sazonalidade e a flutuação populacional de Nyssodrysina lignaria, em localidades do Estado do Paraná, relacionando-a a elementos bióticos e abióticos. 
Neste estudo, a sazonalidade é conceituada como sendo a variação de abundância da população decorrente de fenômenos abióticos influenciados pelas estações do ano (principalmente a temperatura e o fotoperíodo, nos locais de maior latitude e altitude), ao longo de todo um ano; e a flutuação populacional como sendo a variação pontual de abundância da população caracterizada pelas alterações ocasionais (pontuais) mais profundas da tendência natural (sazonal) dos fenômenos climáticos, no decorrer de uma estação do ano.

\section{MATERIAL E MÉTODOS}

O material para estudo foi obtido em dois períodos de coletas intensivas realizadas no Estado do Paraná. O primeiro período refere-se à coleta realizada pelo projeto de Levantamento da Fauna Entomológica no Estado do Paraná (PROFAUPAR), durante um ano, de agosto de 1986 a julho de 1987, em oito localidades (Antonina, São José dos Pinhais, Colombo, Ponta Grossa, Telêmaco Borba, Jundiaí do Sul, Guarapuava e Fênix), utilizando armadilha malaise. A coleta (neste texto muitas vezes referida como PROFAUPAR 86/87) tem toda a sua metodologia, descrição dos locais, bem como número de coletas mensais, apresentadas em MARINONI \& DUtra (1993).

O segundo período corresponde à coleta, também com armadilha malaise, realizada em Ponta Grossa (Parque Estadual de Vila Velha), no mesmo local do PROFAUPAR (86/87), 13 anos após. A coleta (neste texto muitas vezes referida como Ponta Grossa 99/00), durou um ano, de setembro de 1999 a agosto de 2000. O local está situado na região dos Campos Gerais, definida por МАAск (1981) como de "campos limpos (estepes de gramíneas com capões, com matas ciliares ou galerias ao longo dos rios e arroios); também é zona de araucária com epífitas e palmáceas"; na classificação de Veloso \& Góes-Filho (1982), adotada pelo IBGE (1992), é enquadrada como uma Floresta Ombrófila Mista Montana; e pela classificação de zonas de vida de Holdridge, segundo Milano et al. (1987), é considerada como pertencendo a uma Floresta Úmida Temperada.

As armadilhas foram instaladas em cinco diferentes pontos, com características florísticas próprias, produto de diferentes estágios serais ou de diferentes condições ambientais por manejo. Estes pontos, cujas situações geográficas estão apresentadas na figura 1, têm as características mais importantes descritas abaixo.

Área de borda - situada em borda de mata. A área de campo, adjacente à mata, foi mantida por desbaste contínuo (pelo menos semestral), exceto por uma faixa de $10 \mathrm{~m}$ de raio em torno da armadilha, que permaneceu intocada durante o período. A área de mata está em estágio intermediário de sucessão.

Área de araucária - distante $240 \mathrm{~m}$ da borda, aproximadamente. Trata-se de um povoamento florestal de Araucaria angustifolia (pinheiro-do-paraná), dominante em biomassa, cujo manejo de limpeza deixou de ser feito há mais de 20 anos.

Área fase 1 - a $335 \mathrm{~m}$ da borda, aproximadamente. Área de aproximadamente 15 hectares, anteriormente utilizada para culturas agrícolas sazonais, como milho e feijão. Em processo de regeneração natural desde 1984. Encontra-se numa fase inicial a intermediária de sucessão vegetal.

Área fase 2 - distante $400 \mathrm{~m}$ da borda, aproximadamente. Esta área serviu de base, em 1986/1987, para a coleta realizada pelo PROFAUPAR (86/87). Mata primária alterada pela retirada de várias essências vegetais, como pinheiro-do-paraná, imbuia, canelas diversas e algumas mirtáceas. A sucessão vegetal, dependendo do local observado, varia de intermediária a avançada. Área fase 3 - a $1200 \mathrm{~m}$ da armadilha situada na área de borda, aproximadamente, e a $90 \mathrm{~m}$ da borda da mata. Mata primária alterada por cortes seletivos. É a mais bem preservada dentre todas, com estrutura definida e mais homogênea, própria de floresta madura. As características da flora são muito semelhantes à da área fase 2 , com uma maior densidade de araucária. As imbuias apresentam-se maiores (altura e massa), bem como as demais lauráceas (canelas).

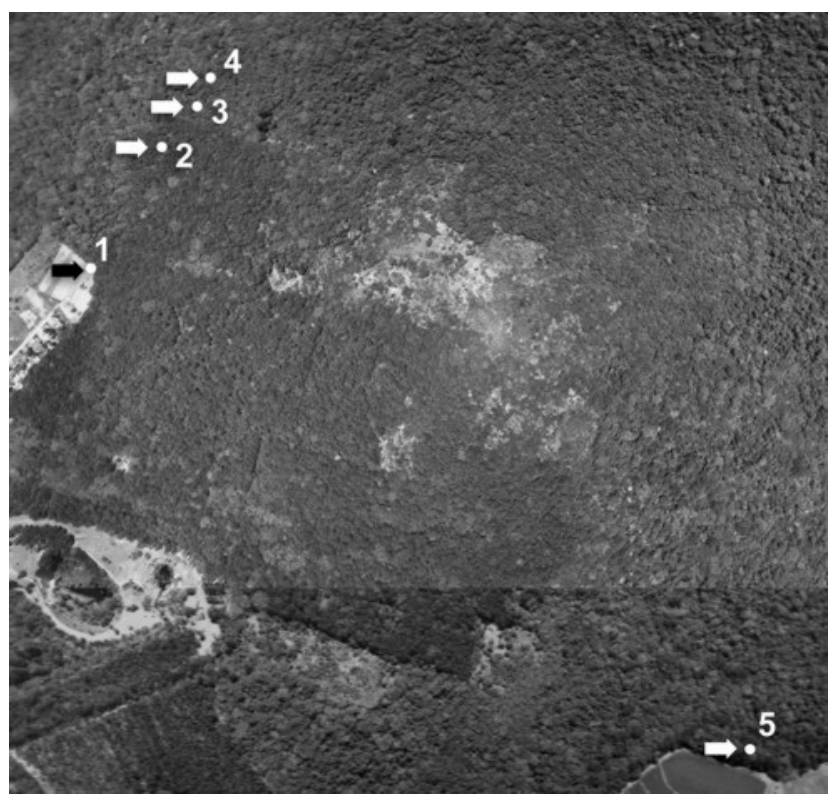

Figura 1. Fotografia área de parte do Parque Estadual de Vilha Velha, Ponta Grossa, Paraná, com a localização das cinco armadilhas malaise: (I) borda de mata, (2) araucária (povoamento de pinheiro-do-paraná), (3) fase 1 (antiga área com culturas agrícolas sazonais), (4) fase 2 (área preservada, objeto de levantamento anterior pelo projeto Levantamento da Fauna Entomológica no Estado do Paraná - PROFAUPAR), (5) fase 3 (área preservada).

Nestas cinco áreas a metodologia de coleta foi semelhante à empregada pelo PROFAUPAR 86/87, com a retirada semanal do material (morto e conservado em álcool a 70\%) (Tab. I). No período houve perda de material de duas semanas referentes à armadilha da área de borda (18/10/1999 e 06/03/2000) e duas semanas referentes à armadilha da área fase $3(03 / 04 / 2000$ e $10 / 04 / 2000)$, causadas pela queda de galhos sobre as armadilhas e ainda pela derrubada causada por animais.

As análises foram baseadas em valores médios semanais de indivíduos capturados em cada mês (indivíduos capturados por mês / número de semanas de efetiva coleta). Estes valores médios de captura foram comparados aos valores médios mensais de variáveis meteorológicas (temperatura máxima, umidade relativa do ar) através do cálculo de regressão múltipla (coeficiente de determinação > 0,50; nível de probabilidae 
Tabela I. Número de coletas por mês, através de armadilha malaise, de setembro de 1999 a agosto de 2000, em cinco diferentes áreas de Vila Velha, Ponta Grossa, Paraná. (Bd) Área de borda de mata, (Ar) área de araucária, (F1) área fase 1, (F2) área fase 2, (F3) área fase 3.

\begin{tabular}{cccccc}
\hline Mês & $\mathrm{Bd}$ & $\mathrm{Ar}$ & $\mathrm{F} 1$ & $\mathrm{~F} 2$ & $\mathrm{~F} 3$ \\
\hline Set/1999 & 4 & 4 & 4 & 4 & 4 \\
Out/1999 & 3 & 4 & 4 & 4 & 4 \\
Nov/1999 & 5 & 5 & 5 & 5 & 5 \\
Dez/1999 & 4 & 4 & 4 & 4 & 4 \\
Jan/2000 & 5 & 5 & 5 & 5 & 5 \\
Fev/2000 & 4 & 4 & 4 & 4 & 4 \\
Mar/2000 & 3 & 4 & 4 & 4 & 4 \\
Abr/2000 & 4 & 4 & 4 & 4 & 2 \\
Mai/2000 & 5 & 5 & 5 & 5 & 5 \\
Jun/2000 & 4 & 4 & 4 & 4 & 4 \\
Jul/2000 & 5 & 5 & 5 & 5 & 5 \\
Ago/2000 & 4 & 4 & 4 & 4 & 4 \\
\hline
\end{tabular}

$<0,10)$. Os dados de temperatura máxima e temperatura mínima indicaram ser correlacionados (coeficientes de correlação linear " $r$ ", para as várias localidades, entre 0,97 e 0,81), levando à aplicação apenas da temperatura máxima nos cálculos de regressão múltipla. Para destacar graficamente a flutuação populacional mensal, expressa em gráficos de colunas, foi utilizada a curva de tendência polinomial de sexta ordem, utilizando o programa Excel (Microsoft 1997); o ajustamento da curva é indicado através do coeficiente de regressão $\mathrm{R}^{2}$. Para evidenciar as relações de semelhança dos dados de flutuação populacional entre os pares de localidades, obtidas através do coeficiente de correlação linear, foi utilizado o método de agrupamento por média aritmética não ponderada (UPGMA). Como método complementar, para comparação da sazonalidade entre localidades, foi utilizada a análise por componentes principais, e a árvore de conexão mínima. Ambas análises numéricas foram desenvolvidas utilizando o programa NTSYS-pc, versão 1.80 (RoHLF 1994).

\section{RESULTADOS}

Durante o ano 86/87, nas oito localidades do PROFAUPAR, foram capturados 384 indivíduos de Nyssodrysina lignaria (Tab. II). As localidades de Fênix, Jundiaí do Sul, Ponta Grossa e Guarapuava foram as que apresentaram os maiores valores de abundância, com 132, 61, 54 e 49 indivíduos, respectivamente. Em São José dos Pinhais, a espécie esteve minimamente representada com apenas quatro exemplares. Em Ponta Grossa, durante o ano 1999/2000, foram capturados 259 indivíduos (Tab. III) nas cinco diferentes áreas. A área fase 3, reconhecida como a mais preservada, e as áreas fase 1 e de araucária apresentaram os maiores valores de abundância. $\mathrm{Na}$ área fase 2 , onde anteriormente havia sido realizada a coleta pelo PROFAUPAR (86/87), o número de indivíduos foi de 53 exemplares. Na área de borda foram capturados apenas 20 .

Os valores de captura média reunindo todas a localidades do PROFAUPAR (86/87) e todas as áreas de Ponta Grossa (99/00) indicam uma maior abundância nos meses de primavera e verão (Figs 2 e 10), sendo no PROFUPAR em novembro e dezembro de 1986 e, em Ponta Grossa, em dezembro de 1999 e janeiro de 2000.

Tabela II. Nyssodrysina lignaria. Número de indivíduos capturados em oito localidades do Paraná, no período de agosto de 1986 a julho de 1987. Dados entre parênteses representam a captura média semanal de cada um dos meses. (AN) Antonina, (SJ) São José dos Pinhais, (CO) Colombo, (PG) Ponta Grossa, (TB) Telêmaco Borba, (JU) Jundiaí do Sul, (GU) Guarapuava, (FE) Fênix.

\begin{tabular}{|c|c|c|c|c|c|c|c|c|c|c|c|c|c|c|c|c|c|}
\hline & \multicolumn{2}{|c|}{ AN } & \multicolumn{2}{|r|}{ S) } & \multicolumn{2}{|c|}{$\mathrm{CO}$} & \multicolumn{2}{|r|}{ PG } & \multicolumn{2}{|r|}{ TB } & \multicolumn{2}{|r|}{ JU } & \multicolumn{2}{|c|}{ GU } & \multicolumn{2}{|r|}{$\mathrm{FE}$} & \multirow{2}{*}{$\frac{\text { Total }}{10}$} \\
\hline Ago/1986 & 0 & $(0,00)$ & 0 & $(0,00)$ & 0 & $(0,00)$ & 0 & $(0,00)$ & 0 & $(0,00)$ & 5 & $(1,25)$ & 0 & $(0,00)$ & 5 & $(1,25)$ & \\
\hline Set/1986 & 2 & $(0,40)$ & 0 & $(0,00)$ & 3 & $(0,60)$ & 4 & $(0,80)$ & 7 & $(1,40)$ & 11 & $(2,20)$ & 0 & $(0,00)$ & 12 & $(2,40)$ & 39 \\
\hline Out/1986 & 3 & $(0,75)$ & 0 & $(0,00)$ & 8 & $(2,00)$ & 11 & $(2,75)$ & 1 & $(0,25)$ & 12 & $(3,00)$ & 3 & $(0,75)$ & 28 & $(7,00)$ & 66 \\
\hline Nov/1986 & 5 & $(1,25)$ & 0 & $(0,00)$ & 5 & $(1,25)$ & 9 & $(2,25)$ & 2 & $(0,50)$ & 13 & $(3,25)$ & 3 & $(0,75)$ & 29 & $(7,25)$ & 66 \\
\hline Dez/1986 & 4 & $(0,80)$ & 2 & $(0,40)$ & 3 & $(0,60)$ & 8 & $(1,60)$ & 2 & $(0,40)$ & 5 & $(1,00)$ & 14 & $(2,80)$ & 13 & $(2,60)$ & 51 \\
\hline Jan/1987 & 9 & $(3,00)$ & 0 & $(0,00)$ & 6 & $(1,50)$ & 1 & $(0,25)$ & 0 & $(0,00)$ & 0 & $(0,00)$ & 7 & $(1,75)$ & 7 & $(1,75)$ & 30 \\
\hline Fev/1987 & 3 & $(0,75)$ & 0 & $(0,00)$ & 1 & $(0,25)$ & 4 & $(0,50)$ & 0 & $(0,00)$ & 1 & $(0,25)$ & 4 & $(1,00)$ & 4 & $(1,00)$ & 17 \\
\hline Mar/1987 & 2 & $(0,40)$ & 2 & $(0,40)$ & 6 & $(1,20)$ & 13 & $(2,60)$ & 5 & $(1,00)$ & 3 & $(0,60)$ & 8 & $(1,60)$ & 12 & $(2,40)$ & 51 \\
\hline Abr/1987 & 0 & $(0,00)$ & 0 & $(0,00)$ & 0 & $(0,00)$ & 1 & $(0,30)$ & 3 & $(0,75)$ & 2 & $(0,50)$ & 10 & $(2,50)$ & 3 & $(0,75)$ & 19 \\
\hline Mai/1987 & 0 & $(0,00)$ & 0 & $(0,00)$ & 0 & $(0,00)$ & 0 & $(0,00)$ & 0 & $(0,00)$ & 1 & $(0,25)$ & 0 & $(0,00)$ & 4 & $(1,00)$ & 5 \\
\hline Jun/1987 & 0 & $(0,00)$ & 0 & $(0,00)$ & 0 & $(0,00)$ & 0 & $(0,00)$ & 0 & $(0,00)$ & 3 & $(0,60)$ & 0 & $(0,00)$ & 4 & $(0,80)$ & 7 \\
\hline Jul/1987 & 4 & $(1,00)$ & 0 & $(0,00)$ & 0 & $(0,00)$ & 3 & $(0,75)$ & 0 & $(0,00)$ & 5 & $(1,25)$ & 0 & $(0,00)$ & 11 & $(2,75)$ & 23 \\
\hline Total & 32 & & 4 & & 32 & & 54 & & 20 & & 61 & & 49 & & 132 & & 384 \\
\hline
\end{tabular}


Tabela III. Nyssodrysina lignaria. Número de indivíduos capturados em cinco diferentes áreas de Vila Velha, Ponta Grossa, Paraná, no período de setembro de 1999 a agosto de 2000. Dados entre parênteses representam a captura média semanal de cada um dos meses. (Bd) Área de borda de mata, (Ar) área de araucária, (F1) área fase 1, (F2) área fase 2, (F3) área fase 3.

\begin{tabular}{lcccccc}
\hline & $\mathrm{Bd}$ & $\mathrm{Ar}$ & $\mathrm{F} 1$ & $\mathrm{~F} 2$ & $\mathrm{~F} 3$ & Total \\
\hline Set/1999 & $0(0,00)$ & $2(0,50)$ & $3(0,75)$ & $0(0,00)$ & $2(0,50)$ & 7 \\
Out/1999 & $0(0,00)$ & $2(0,50)$ & $5(1,25)$ & $6(1,50)$ & $1(0,25)$ & 14 \\
Nov/1999 & $2(0,40)$ & $11(2,20)$ & $6(1,20)$ & $9(1,80)$ & $9(1,80)$ & 37 \\
Dez/1999 & $2(0,50)$ & $6(1,50)$ & $11(2,75)$ & $10(2,50)$ & $13(3,25)$ & 42 \\
Jan/2000 & $2(0,40)$ & $8(1,60)$ & $11(2,20)$ & $5(1,00)$ & $17(3,40)$ & 43 \\
Fev/2000 & $1(0,25)$ & $5(1,25)$ & $5(1,25)$ & $7(1,75)$ & $8(2,00)$ & 26 \\
Mar/2000 & $0(0,00)$ & $6(1,50)$ & $13(3,25)$ & $5(1,25)$ & $3(0,75)$ & 27 \\
Abr/2000 & $0(0,00)$ & $6(1,50)$ & $2(0,50)$ & $4(1,00)$ & $2(0,50)$ & 14 \\
Mai/2000 & $6(1,20)$ & $3(0,60)$ & $1(0,20)$ & $5(1,00)$ & $7(1,40)$ & 22 \\
Jun/2000 & $3(0,75)$ & $3(0,75)$ & $3(0,75)$ & $1(0,25)$ & $1(0,25)$ & 11 \\
Jul/2000 & $2(0,40)$ & $6(1,20)$ & $0(0,00)$ & $1(0,20)$ & $0(0,00)$ & 9 \\
Ago/2000 & $2(0,50)$ & $3(0,75)$ & $2(0,50)$ & $0(0,00)$ & $0(0,00)$ & 7 \\
\hline Total & 20 & 61 & 62 & 53 & 63 & 259 \\
\hline
\end{tabular}

As figuras 3 a 9 representam os valores de captura média (colunas) de cada uma das sete localidades objeto do levantamento do PROFAUPAR. A localidade de São José dos Pinhais, em razão do inexpressivo número de indivíduos capturados (quatro), não foi considerada neste estudo. Na maioria dos locais, a linha de tendência polinomial tornou bem evidente uma maior abundância de exemplares no conjunto dos meses de primavera e verão. Em Telêmaco Borba e Guarapuava, foi capturado um número de indivíduos nos meses do início do outono (março e abril), próximo àquele dos meses de primavera-verão. O número de indivíduos capturado em Guarapuava, no mês de abril, resultou numa linha de tendência diferente das observadas nos gráficos dos outros locais. Em Ponta Grossa também se capturou um alto número de indivíduos em março, mas a linha de tendência, pela forte expressão da abundância nos meses de primavera e verão, foi semelhante à das demais localidades. Nas figuras, as linhas de tendência (colunas) permitem visualizar a existência de outro pico de abundância ao longo do período de um ano, além daquele observado nos meses de primavera e verão. $\mathrm{Na}$ somatória do número de indivíduos capturados em todas as localidades (Fig. 2), bem como na maioria das localidades, verifica-se a existência de um pico de maior ou menor expressão nos meses do fim do verão e início de outono (março a maio). Ponta Grossa, Guarapuava e Fênix (Figs 5, 8 e 9) mostram um pico no início do outono (março e abril). Este mesmo fenômeno, apesar de pouco expressivo, pode ser também observado na localidade de Jundiaí do Sul (Fig 7). Em Colombo e Telêmaco Borba (Figs 4 e 6), apesar do número de indivíduos capturados ter sido menor que nas localidades acima, houve também um pico de abundância no início do outono. Apenas na localidade de Antonina tal pico não ficou caracterizado. No fim do período de coleta, julho de 1987, na maioria das localidades verificou-se um aumento da abundância.

As figuras 10 a 15 representam os dados de captura nas cinco áreas de Ponta Grossa, durante o ano 99/00. Todos os ambientes apresentam a linha de tendência polinomial de sexta ordem indicando a maior presença da espécie nos meses de primavera e verão, exceto pelos dados de captura na borda de mata (Fig. 11), que foi de cerca de $1 / 3$ do número de exemplares de cada uma das outras áreas. A análise dos valores de captura média (colunas) também evidencia um segundo pico nos meses de fim de verão e início de outono, variando de março a maio, conforme a área. Ocorreu uma exceção na área fase 2 (Fig. 14), em que o pico ocorreu no mês de fevereiro. Esta área é a mesma onde havia sido feita a coleta durante o período de $86 / 87$, pelo PROFAUPAR. Na figura 10, que reúne os valores de todas as áreas, o pico do outono está nítido.

Abundância e as variáveis meteorológicas. A análise de regressão múltipla (Tab. IV) mostrou que, nas localidades de Colombo e Ponta Grossa (1986/1987) houve uma relação significativa (coeficiente de determinação R2 > 0,500; $p<0,10$ ) da abundância tanto com a temperatura (temperatura mais alta/ mais indivíduos capturados) como com a umidade do ar (menos umidade/mais indivíduos capturados). Em Guarapuava, também houve uma relação significativa com a temperatura e com a umidade, porém a relação desta foi positiva, ou seja, maior abundância com maior umidade. Em Jundiaí do Sul e Fênix, a análise de regressão indicou uma maior relação da abundância com a umidade do ar (menos umidade/mais indivíduos). Antonina e Telêmaco Borba apresentaram baixos coeficientes

Tabela IV. Regressão múltipla entre abundância e variáveis meteorológicas (temperatura e umidade relativa do ar). Em negrito, destaque para ${ }^{*}=$ probabilidade $>0,10 ; \mathrm{R} 2$, coeficiente de determinação $>0,500$.

\begin{tabular}{|c|c|c|c|}
\hline \multirow{2}{*}{ Localidades } & \multicolumn{2}{|c|}{ Coeficiente de regressão parcial } & \multirow{2}{*}{ R2 } \\
\hline & Temperatura & Umidade & \\
\hline Colombo & 0,546 * & $-0,490 *$ & 0,566 \\
\hline Ponta Grossa, & 0,481 * & $-0,576$ * & 0,678 \\
\hline Guarapuava & 0,820 * & 0,428 * & 0,649 \\
\hline Jundiaí do Sul & $-0,069$ & $-0,888$ * & 0,747 \\
\hline Fênix & 0,208 & $-0,627 *$ & 0,534 \\
\hline Antonina & 0,578 * & $-0,272$ & 0,441 \\
\hline Telêmaco Borba & 0,118 & $-0,429$ & 0,226 \\
\hline Área de borda de mata & $-0,413$ & 0,176 & 0,178 \\
\hline Área de araucária & 0,520 & $-0,113$ & 0,263 \\
\hline Área fase 1 & 0,723 * & 0,176 & 0,596 \\
\hline Área fase 2 & 0,613 * & 0,018 & 0,380 \\
\hline Área fase 3 & 0,731 * & 0,003 & 0,535 \\
\hline
\end{tabular}



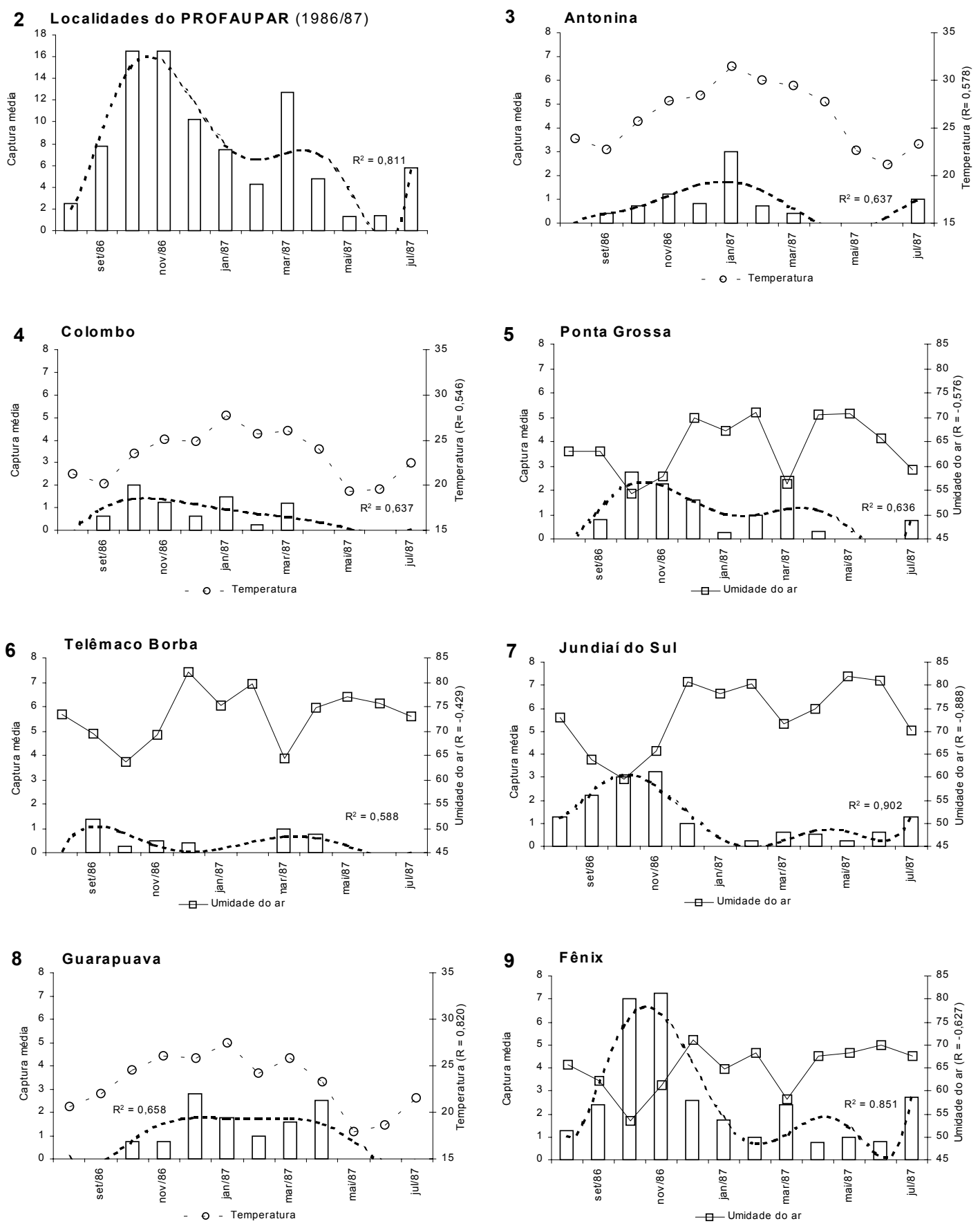

Figuras 2-9. Sazonalidade de Nyssodrysina lignaria no Estado do Paraná, no período de agosto de 1986 a julho de 1987 (PROFAUPAR). (2) Gráfico com a soma das capturas médias das sete localidades; (3-9) gráficos com a captura média de cada localidade e a variável meteorológica com a qual foi registrado o maior coeficiente de regressão parcial $(=\mathrm{R})$. Linha de tendência da sazonalidade durante o período está representada pela linha grossa tracejada, com o $\mathrm{R}^{2}$ indicativo do valor de ajuste da linha de tendência.

de determinação, no entanto, em Antonina, o coeficiente de regressão parcial para a temperatura foi significativo. Para os dados de captura em Ponta Grossa (99/00) somente duas áreas, fase 1 e fase 3 , tiveram um coeficiente de determinação superior a 0,500 . Porém, houve uma relação significativa da captura com a temperatura nas áreas fase 1, 2 e 3.

Revista Brasileira de Zoologia 20 (1): 141 - 152, março de 2003 


\section{DISCUSSÃO}

Dois enfoques devem ser considerados para a interpretação dos dados referentes à sazonalidade de Nyssodrysina lignaria. Um refere-se ao posicionamento geográfico dos pontos onde se realizaram as coletas, com as implicações climáticas decorrentes. O segundo enfoque diz respeito aos comportamentos alimentar e ontogenético da espécie. Apesar de não haver como minimizar a importância da interação desses fatores como condicionadores da flutuação populacional, os mesmos serão discutidos separadamente. Esta abordagem segue, por analogia, o raciocínio de Pianka (1966) que, ao rever conceitos sobre os gradientes latitudinais na diversidade de espécies, escreveu: "it is useful first to consider and assess each of the components of control of diversity in isolation, before attempting various mixtures".

Todas as localidades onde se realizaram as coletas estão situadas abaixo do Trópico de Capricórnio, exceto Jundiaí do Sul, que está na mesma linha. Nestas latitudes, o fotoperíodo torna-se importante, com os dias sensivelmente mais longos que as noites nos meses de verão. Em função da latitude e da altitude, algumas das localidades, como Colombo, Ponta Grossa, Guarapuava têm ciclos de temperatura bem nítidos, com a época de inverno sendo marcada pela ocorrência de geadas; estas muito raramente ocorrendo em Jundiaí do Sul, Fênix e Antonina, principalmente em razão da altitude (MAACK 1981, Marinoni \& DUtra 1993).

As relações entre a abundância e as variáveis meteorológicas foram diferentes de acordo com as localidades do PROFAUPAR (Figs 3 a 9). Nos lugares mais frios e com características climáticas mais semelhantes, como Colombo, Ponta Grossa e Guarapuava (MARINONI \& DuTRA 1993), a abundância esteve associada significativamente à temperatura e à umidade relativa do ar. Nos lugares mais quentes, como Jundiaí do Sul e Fênix, a maior relação foi com a umidade relativa do ar quando, em ocasiões de pouca umidade, houve maior coleta de indivíduos.

Nos locais de temperatura média mais fria, apesar da tendência de um ajustamento maior dos valores mais altos de abundância às temperaturas mais altas, verificou-se também um aumento de abundância nos meses de umidade relativa mais baixa, como em Ponta Grossa e Colombo. Na maioria das localidades do PROFAUPAR (86/87), o segundo maior pico de abundância ocorreu no mês de março que coincidiu com leve aumento da temperatura e queda da umidade do ar. Em Guarapuava, apesar de ter havido o mesmo fenômeno meteorológico, a maior captura se deu em abril. Outro dado a considerar, que relaciona a abundância à temperatura, é o referente a um aumento de abundância em julho de 1987, acompanhando o aumento da temperatura ocorrido em todas as localidades.

Jundiaí do Sul e Fênix situam-se em uma área considerada como de transição climática, raramente sofrendo a ação do frio, principalmente de geadas; estão situadas quase sobre o Trópico de Capricórnio em altitudes inferiores a $500 \mathrm{~m}$, acima do nível do mar. As duas citadas localidades estão entre aquelas de mais altos valores de temperatura e de mais baixos percentuais de umidade relativa do ar dentre as levantadas pelo PROFAUPAR, e que as análises do conjunto das variáveis meteorológicas indicaram ser muito semelhantes climaticamente (MARINONI \& Dutra 1993). Os gráficos de flutuação populacional (Figs 7 e 9) dos dois locais são muito semelhantes, destacando como característica mais notável os altos coeficientes de relação com a umidade relativa do ar, no que diferem das outras localidades. Assumindo que a temperatura não tenha sido fator limitante para o desenvolvimento da espécie em Jundiaí do Sul e Fênix, o fotoperíodo teria sido o fator mais importante para, associado ao período reprodutivo das plantas hospedeiras, condicionar os picos de maior abundância aos meses de primavera e verão.

O fato dos valores de abundância terem apresentado uma relação significativa com os de umidade relativa (ambiente mais seco - mais indivíduos coletados), em quatro locais (Colombo, Ponta Grossa, Jundiaí do Sul e Fênix), apresenta-se como um elemento de destaque e parece indicar uma característica ligada ao comportamento de vôo da espécie. Haveria uma maior facilidade de vôo em ambiente seco do que em ambiente úmido. Este fato permite alertar para que a umidade relativa do ar deva ser considerada como um fator importante nas avaliações sobre os dados de captura pontuais, que tenham sido obtidos através de métodos que impliquem no vôo dos indivíduos, como é o caso da armadilha malaise. A relação entre a diminuição da umidade relativa do ar e o aumento de captura de indivíduos foi observado também em Syrphidae (Diptera) (GILBERT 1985, Maier \& Waldbauer 1979, Marinoni \& Bonatto 2002) e em Muscidae (Diptera) (CostacurTa et al. no prelo).

Martins (1971) reconheceu a área de transição climática, acima citada, como sendo o limite sul da distribuição de muitas espécies de Ibidionini (Cerambycidae), que vivem na área setentrional da Mata Atlântica e o limite norte de várias espécies da área meridional. Apesar dos limites norte e sul da distribuição geográfica de Nyssodrysina lignaria estarem muito acima e abaixo dessa área (Monné 1995), a semelhança entre os dados de sazonalidade observados em Jundiaí do Sul e Fênix, diferenciados de todas as demais localidades estudadas, é uma evidência a mais que vem a corroborar a importância da área como zona de transição para a fauna de Cerambycidae.

A maior relação da captura média com a temperatura em três áreas (fase 1, fase 2 e fase 3 ) de Ponta Grossa, durante o ano 99/00, foram coerentes com os resultados obtidos em áreas mais frias estudadas pelo PROFAUPAR 86/87, como Colombo, Ponta Grossa, Guarapuava (MARINONI \& DUTRA 1993). As outras duas áreas, com baixos coeficientes de determinação, foram a área de borda de mata (Fig. 11) e a área de araucária (Fig.12); a primeira área sendo atípica para avaliação do comportamento de $N$. lignaria, que tem o seu desenvolvimento ontogenético em fruto de árvores; e a segunda, teve uma maior relação também com a temperatura, com o coeficiente de regressão parcial relativamente alto, porém inferior ao das áreas fase 1 a fase 3 , e não-significativo.

Comparando os dados de captura obtidos no ano 86/87 (PROFAUPAR) (Tab. II) com aqueles obtidos no mesmo local, ou seja, na área fase 2 , no ano 99/00 (Tab. III) constata-se que houve um número semelhante de indivíduos capturados (54/ 53). Em 86/87 (Fig. 5), a maior captura média ocorreu no mês de outubro, caindo muito até janeiro, para alcançar um número mais alto em março; em 99/00 (Fig. 14), a maior abundância foi em dezembro, decaindo em janeiro e alcançando um segundo pico já em fevereiro. O atraso do pico de maior abundância de outubro em 86/87 para dezembro em 99/00 é coerente com a variação da temperatura nos dois períodos (Fig. 16). Em $86 / 87$, o aumento da temperatura foi gradativo desde setembro, enquanto que em 99/00, houve um atraso na elevação da temperatura, que só ocorreu em dezembro. Em 
10 Ponta Grossa (1999/2000) - Total
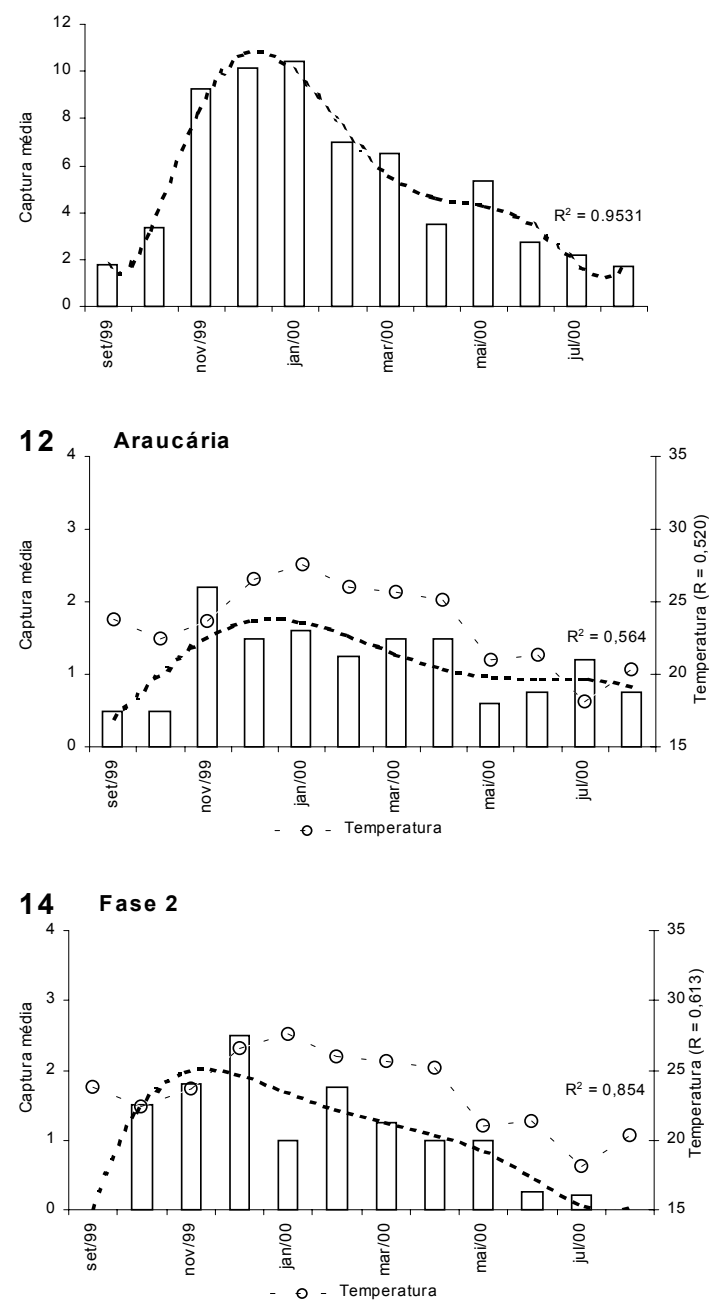
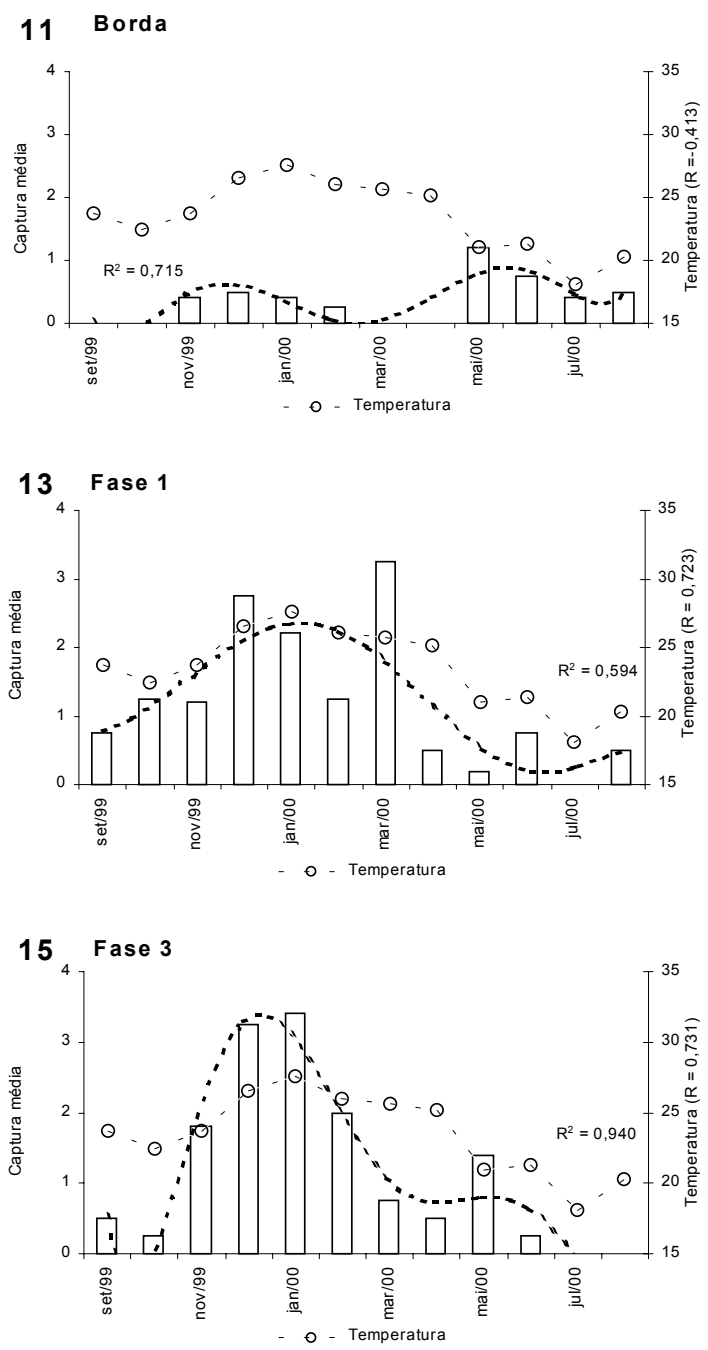

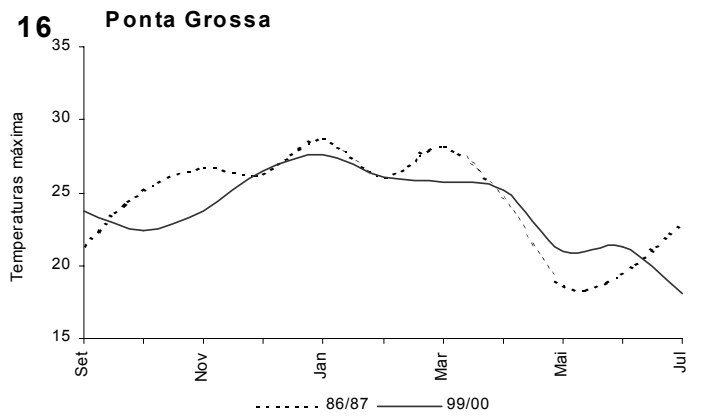

Figuras 10-16. Sazonalidade de Nyssodrysina lignaria em cinco áreas com diferentes características vegetais, em Vila Velha, Ponta Grossa, Paraná. durante o período de setembro de 1999 a agosto de 2000. 10. Gráfico com a soma das capturas médias das cinco áreas. (11-15) Gráficos com a captura média de cada localidade e a variável meteorológica com a qual foi registrado o maior coeficiente de regressão parcial $(=\mathrm{R})$. Linha de tendência da sazonalidade durante o período está representada pela linha grossa tracejada, com o $\mathrm{R}^{2}$ indicativo do valor de ajuste da linha de tendência; (16) temperatura máxima observada em Vila Velha, Ponta Grossa, nos períodos de $1986 / 87$ e 1999/2000. 
86/87, em janeiro, o número de indivíduos coletados foi muito pequeno, coincidindo com uma leve queda da temperatura; esta mesma queda de coleta ocorreu em 99/00, porém sem que tenha havido queda da temperatura.

Constata-se, assim, que a sazonalidade de $N$. lignaria está ajustada às condições de clima temperado. Os maiores valores de abundância sendo observados nos meses de primavera e verão, coincidindo com os valores mais altos de temperatura e com os maiores períodos de luz diária, em áreas de maior latitude (Wolda 1988).

Estes fatores abióticos também têm forte influência no período reprodutivo das plantas (ODum 1988, RosensweIG 1995), que por sua vez condicionam o ciclo reprodutivo de Nyssodrysina lignaria, cujas larvas alimentam-se de frutos. O conhecimento atual indica que o desenvolvimento larval deve se dar em frutos de Theobroma spp. e de Inga spp., principalmente nestas (BONDAR 1939, MARINONi et al. 2002). Não considerando as espécies de Theobroma, tendo em vista que as mais comuns são encontradas ao norte do Trópico de Capricórnio, distribuídas pela bacia amazônica, a sazonalidade de N. lignaria deve estar mais estreitamente ligada às das espécies de ingá. Até este momento, estão arroladas como plantas hospedeiras de $N$. lignaria, as espécies Inga sessilis (Vell.) (ocorre do sul de Minas Gerais ao Rio Grande do Sul), Inga lushnathiana Bentham (na encosta atlântica, do Rio de Janeiro a Santa Catarina), Inga uruguensis Hooker \& Arnott (de São Paulo ao Rio Grande do Sul) e Inga virescens Bentham (Paraná e Santa Catarina). (Bose 1943, Biezanko \& Bose 1956, di Iorio \& Fuentes 1998, Marinoni et al. 2002). LoRENZI $(1992,1998)$ refere-se ao amadurecimento dos frutos de I. sessilis como ocorrendo de julho até fevereiro; e de $I$. uruguensis, de dezembro a fevereiro. O fruto de $I$. lushnathiana, que também é lenhoso, tem seu amadurecimento ocorrendo entre dezembro e abril (A. Cervi, comunicação pessoal), enquanto que $I$. virescens (reconhecida sua presença em Vila Velha), amadurece seus frutos de dezembro a março (Hatschbach \& Moreira Filho 1972, Burkart 1979). Confrontando com os dados de abundância de $N$. lignaria observa-se que os valores de maior captura de adultos coincide com a fenologia de amadurecimento dos frutos das plantas hospedeiras conhecidas. Não há, no entanto, concordância com os picos de abundância ocorrentes no mês de maio. Há, a possibilidade de que I. marginata Willd. e I. edulis Mart., sendo muito abundantes e de larga distribuição geográfica, e tendo o amadurecimento dos frutos no período de março a maio e a partir de maio, respectivamente, possam ser hospedeiras de N. lignaria.

O pico de abundância do outono observado em diferentes locais deve representar uma segunda população da espécie, não a caracterizando como bivoltina, fenômeno que ocorre em outras espécies de Coleoptera que também se alimentam de sementes, como algumas espécies de Bruchidae (Southgate 1981, IshiHARA 1998). Os únicos dados sobre o período de desenvolvimento ontogenético de $N$. lignaria indicam uma duração de cerca de um ano (MARINONI et al. 2002). Apesar de insuficientes para conclusão, os dados repetem o observado nos vários estudos sobre ontogenia de Cerambycidae, como se referem Duffy (1953, 1960); Linsley (1961); MARINONI (1969) e NAPp (1976, 1977). Referências sobre casos de desenvolvimento larval que duram poucos meses são raros. Em Duffy (1953) há referência a apenas uma espécie, Phytoecia cylindrica (Linnaeus, 1758), com período normal de desenvolvimento larval de poucos meses. Esse mesmo autor referiu-se vagamente à existência de dados sobre espécies com ciclo de vida de aproximadamente dois meses, mas não citou quais. Crawshay (apud Dufry 1953) observou um período curto, porém anormal, de desenvolvimento larval de Tetropium gabrieli Weise, 1905, como conseqüência de aumento de temperatura em laboratório. Матsumoto et al. (2000), também em estudos de laboratório, referem-se à existência de bivoltinismo no ciclo reprodutivo de Xystrocera globosa (Olivier, 1795). LinsLey (1961) refere-se à existência de picos de abundância nas populações de Atimia confusa dorsalis LeConte, 1869 e Saperda horni Joutel, 1902, em épocas diferentes, nas regiões de menor latitude de suas distribuições geográficas, na região Neártica.

Costa \& Link (1988) estudaram a flutuação populacional de Nyssodrysina lignaria, em Santa Maria, Rio Grande do Sul, em seis talhões de quatro essências florestais (eucalipto, acácia, pinus e ipê amarelo) (Fig. 26). Utilizaram armadilhas de impacto, tendo álcool como atrativo. O período de coleta foi de dois anos, de março de 1986 a fevereiro de 1988. Comparando os dados de coleta com aqueles obtidos pelo PROFAUPAR, durante o mesmo período, de agosto de 1986 a julho de 1987, constata-se que em Santa Maria foram capturados 1162 indivíduos, cerca de três vezes mais o que se coletou em oito localidades no PROFAUPAR. Nenhuma das essências florestais foi, até esta data, reconhecida como hospedeira de $N$. lignaria (MARINONi et al. 2002), fato que pode caracterizar o uso do álcool, atrativo empregado na armadilha, como o responsável pelo vôo dos indivíduos, e em grande número, aos diferentes talhões. Em Santa Maria, situada em latitude superior às localidades do Paraná, as influências do fotoperíodo e temperatura também definem a sazonalidade, com maior abundância nos meses de primavera e verão (Fig. 17). Da mesma forma que o observado nos levantamentos do PROFAUPAR (86/87) e PONTA GROssa (99/ 00 ), constata-se a existência de um segundo pico de abundância no outono.

A análise dos gráficos de flutuação populacional, produzidos por CosTA \& LiNK (1988) para cada um dos talhões (Figs 18-23), permite destacar que a captura em áreas próximas tem seus picos de abundância em meses diferentes, da mesma forma como ocorreu em Ponta Grossa. Nesta localidade, o deslocamento do pico foi observado mais nitidamente na área fase 1 (em fase mais recente de sucessão vegetal, anteriormente utilizada para práticas agrícolas sazonais), muito próxima fisicamente da área fase 2 (em condição de maior preservação) (Figs 13 e 14); em Santa Maria, no talhão formado por tabebuia (Fig. 18), houve uma diferença muito grande com relação aos picos observados no talhão de pinus-3 (Fig. 20), ao qual estava fisicamente acolado.

Considerando que o padrão de sazonalidade de climas temperados foi mantido, a irregularidade não pode ser explicada por fatores pontuais de macro-clima relativos à temperatura e umidade relativa do ar, pelo menos em Ponta Grossa (Figs 1215). Como em Ponta Grossa, não houve o uso de atrativos para a captura, a abundância deve estar condicionada a diferentes fases de amadurecimento de frutos de plantas próximas às armadilhas. Em Santa Maria, como os talhões das essências florestais, com um desenvolvimento muito pobre do subbosque, situam-se em área aberta (CosTa \& Link 1988), houve a possibilidade de uma ampla dispersão dos vapores de álcool, que seriam orientados para áreas próximas, onde teriam se criado os indivíduos de N.lignaria.

Em Santa Maria, os resultados da análise de agrupamento 

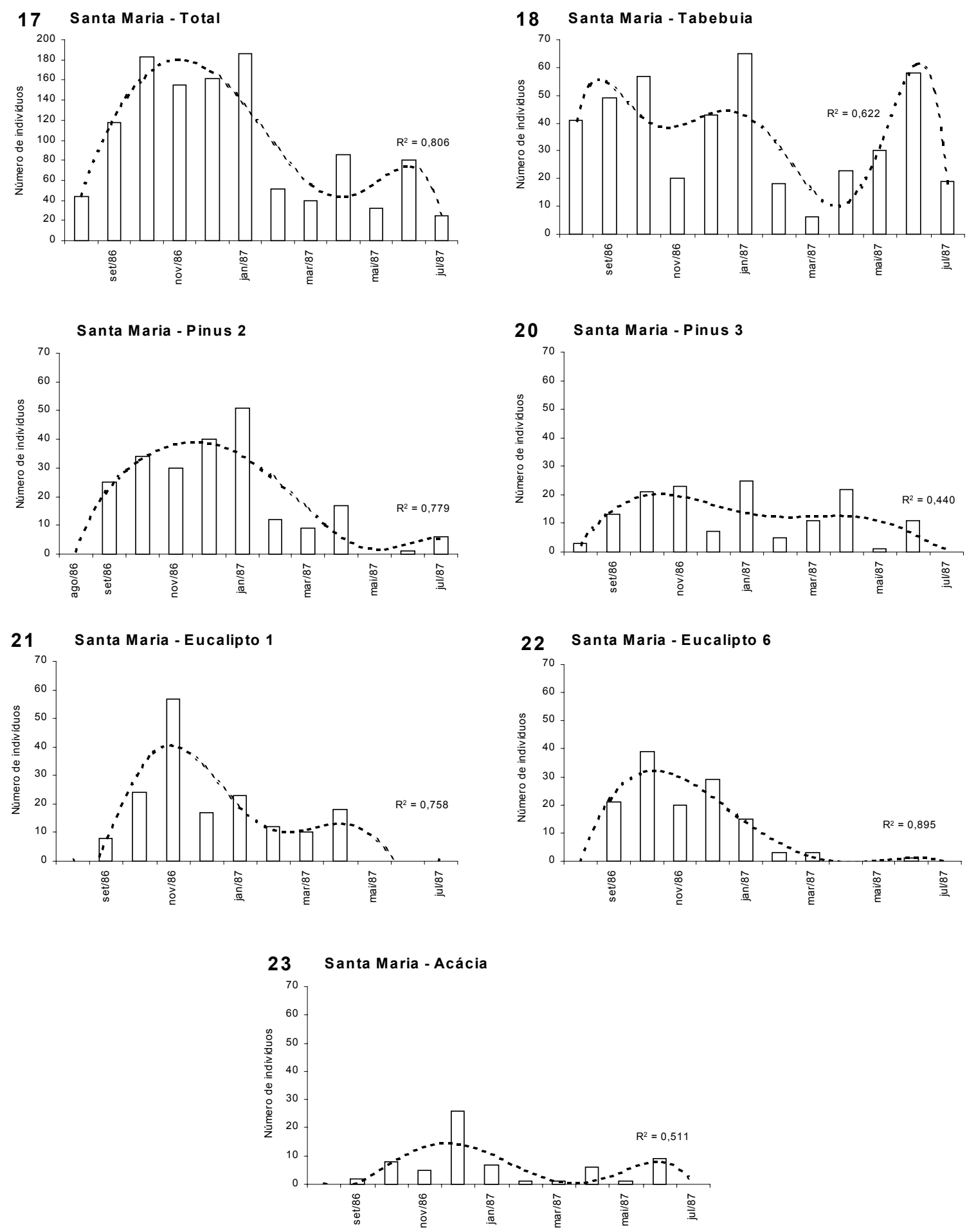

Figuras 17-23. Sazonalidade de Nyssodrysina lignaria em seis talhões com diferentes essências florestais, em Santa Maria, Rio Grande do Sul, no período de agosto de 1986 a setembro de 1987. Linha de tendência da sazonalidade durante o período está representada pela linha grossa tracejada, com o $\mathrm{R}^{2}$ indicativo do valor de ajuste da linha de tendência. Os dados foram extraídos de COSTA \& LINK (1988). 
(Fig. 24) indicam uma maior semelhança entre os talhões de eucalipto-1 e pinus-3 e entre os de eucalipto- 6 e pinus-2, aos quais se agregaram os talhões de acácia e tabebuia. Talhões com as mesmas essências florestais tiveram flutuações populacionais diferentes. O gráfico bidimensional (Fig. 25), resultado da análise por componentes principais, apresenta interessante relação de posicionamento das unidades, comparável ao posicionamento físico dos talhões, conforme croquis com a situação aproximada (Fig. 26). Houve uma relação de maior semelhança entre os talhões posicionados numa mesma face da área física dos experimentos, em oposição à maior semelhança entre os talhões posicionados na face geográfica oposta. Este fato parece reforçar a hipótese de que a diferença de captura observada entre talhões tão próximos quanto o de pinus-3 e o de tabebuia sejam decorrentes da dispersão dos vapores de álcool, que levariam à atração dos adultos de $N$. lignaria criados em áreas próximas.
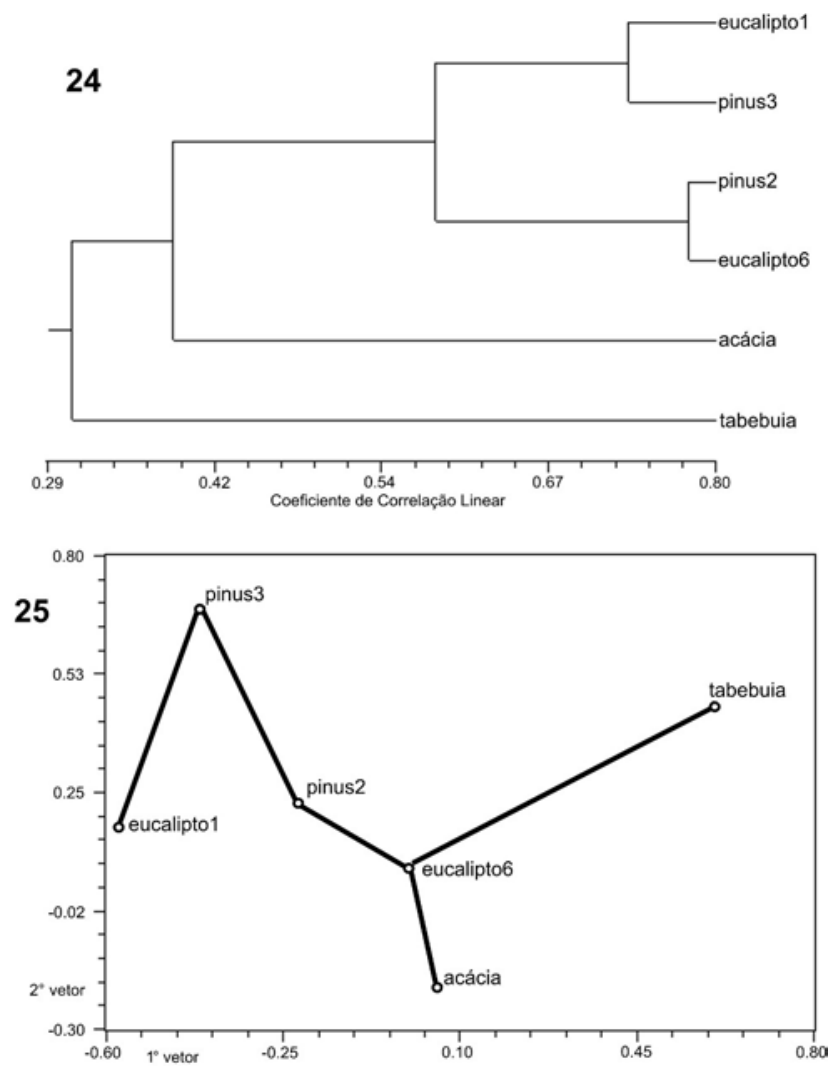

Figuras 24-25. Análise numérica comparando os dados de flutuação populacional de Nyssodrysina lignaria observados nos seis talhões de essências florestais, em Santa Maria, Rio Grande do Sul, durante o período de agosto de 1986 a julho de 1987. Os dados foram extraídos de CosTA \& Link (1988). (24) Dendrograma, com as semelhanças entre os pares de unidades definidas por Coeficiente de Correlação Linear; (25) Gráfico bi-dimensional, a partir de análise por componentes principais, com o primeiro vetor representando $45 \%$, e o segundo vetor, $23 \%$, da porcentagem do traço; ligações entre as áreas definidas por Árvore de Conexão Mínima.

Revista Brasileira de Zoologia 20 (1): 141 - 152, março de 2003

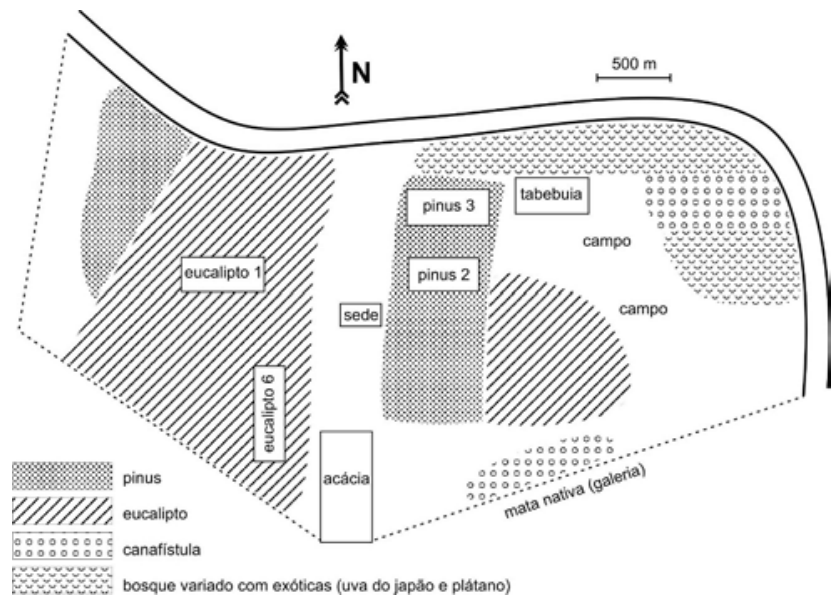

Figura 26. Croquis da situação aproximada dos seis talhões de essências florestais, em Santa Maria, Rio Grande do Sul, segundo Dionísio Link.

Em Ponta Grossa, onde não houve a utilização de atrativos para a captura, o dendrograma (Fig. 27) indica que os pontos de coleta que apresentaram flutuação populacional mais semelhante foram os das áreas consideradas mais preservadas, a área fase 2 e área fase 3 (Figs 14-15). A estas áreas se uniram, pela ordem de semelhança, as áreas fase 1 e de araucária. Muito distante de todas, a área de borda de mata. A maior semelhança da flutuação populacional entre as áreas mais preservadas, e que são as mais distantes fisicamente, favorece a hipótese das áreas terem condições florísticas semelhantes para o suporte do desenvolvimento de $N$. lignaria. A área fase 1 (com anterior atividade agrícola) com um forte pico de abundância em março, situou-se em posição intermediária entre os conjuntos das área fase 2 /área fase 3 e área de borda/área de araucária, conforme indica o resultado da análise por componentes principais (Fig. 28). A área fase 1 , apesar de muito próxima da área 4 (cerca de $80 \mathrm{~m}$ ), mostrou uma flutuação populacional mais semelhante à da área fase 3 , distante cerca de $1200 \mathrm{~m}$.

\section{CONSIDERAÇÕES FINAIS}

A sazonalidade de Nyssodrysina lignaria está ajustada aos padrões de sazonalidade das áreas temperadas, com maior abundância de indivíduos nos meses de primavera-verão. Ficou caracterizado um segundo pico de maior abundância no outono, provavelmente representando uma segunda população da espécie condicionada ao período de frutificação da planta hospedeira. Apresentou uma flutuação populacional decorrente da influência pontual da temperatura e umidade do ar nos locais mais frios, enquanto que, nos locais mais quentes e secos, houve influência mais acentuada da umidade relativa do ar. Em uma mesma região micro-geográfica (Ponta Grossa), a flutuação populacional deve ser produto das diferentes características florísticas. A influência do álcool etílico, como atrativo em armadilhas, deve ser considerada importante nas análises dos dados sobre flutuação populacional (Santa Maria). 

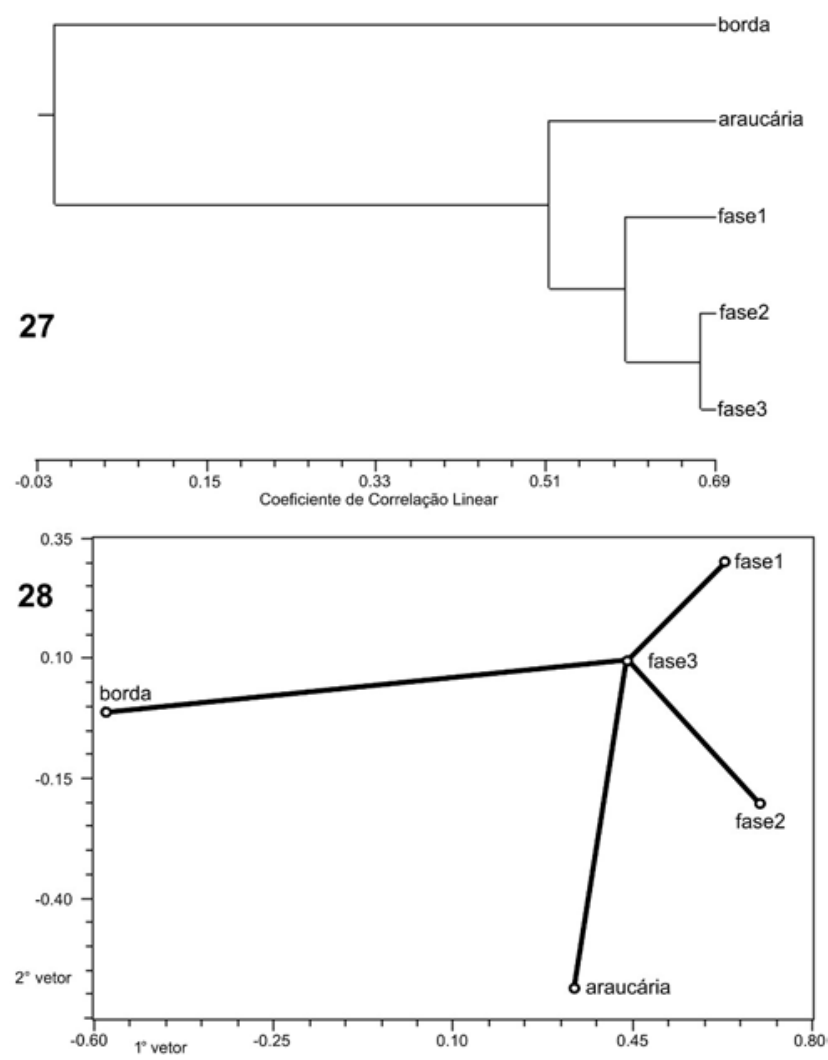

Figuras 27-28. Análise numérica comparando os dados de flutuação populacional de Nyssodrysina lignaria observados em cinco áreas em diferentes estágios de sucessão vegetal, em Vila Velha, Ponta Grossa, Paraná, durante o período de setembro de 1999 a agosto de 2000. (27) Dendrograma, com as semelhanças entre os pares de unidades definidas por Coeficiente de Correlação Linear; (28) Gráfico bi-dimensional, a partir de análise por componentes principais, com o primeiro vetor representando $47 \%$, e o segundo vetor, $27 \%$, da porcentagem do traço; ligações entre as áreas definidas por Árvore de Conexão Mínima.

\section{AGRADECIMENTOS}

Agradecemos a Dionísio Link, pelo envio de importantes informações sobre as características da área onde se realizaram estudos sobre a flutuação populacional de Nyssodrysina lignaria, em Santa Maria, e às críticas formuladas ao manuscrito deste trabalho; à Cibele S.Ribeiro-Costa, pelas discussões sobre sazonalidade, e às sugestões e críticas ao manuscrito, bem como a Elio Corseuil; a Franklin Galvão e à Yoshiko S. Kunyioshi que prestaram inestimável ajuda ao conceituarem as condições de preservação vegetal e a identificarem as espécies vegetais predominantes nos diferentes pontos onde se realizaram as coletas em Vila Velha, Ponta Grossa, no ano 99/00; a Gert G. Hatschbach pela identificação de Inga virescens e a Armando Cervi, pelos dados sobre frutificação e características do fruto de Inga lushnathiana.

\section{REFERÊNCIAS BIBLIOGRÁFICAS}

Biezanko, C.M. \& J.M. BosQ. 1956. Cerambycidae de Pelotas e seus arredores. Agros, Pelotas, 9 (3-4): 3-16.

Bondar, G. 1939. Insetos daninhos e parasitas do cacau da Bahia. Boletim Tecnológico do Instituto do Cacau, Bahia, 5:1112.

Bose, J.M. 1943. Segunda lista de coleópteros de la República Argentina, dañinos a la agricultura. Buenos Aires, Ministério de la Agricultura, Dirección de Sanidad Vegetal, 80p.

Burkart, A. 1979. Leguminosas: Mimosoideas. In: Flora Ilustrada Catarinense. Parte 1, Fascículo LEGU. Itajaí, Ed. R.Reitz, 299p.

Costa, E.C. \& D.Link. 1988. Flutuação populacional de Nyssodrysina lignaria (Bates, 1864) (Coleoptera, Cerambycidae). Nova Prata, Rio Grande do Sul, Anais do VI Congresso Florestal Estadual, p. 541-550.

Costacurta, N.C.; R.C. Marinoni \& C.J.B. Carvalho. (no prelo). Fauna de Muscidae (Diptera) em três localidades do Estado do Paraná, Brasil, capturados por armadilha malaise. Revista Brasileira de Entomologia.

Di IORIO, O.R. \& M.B. FuENTES. 1998. Presence of Nyssodrys lignaria Bates (Coleoptera: Cerambycidae) in the natural reserve of Otamendi, Buenos Aires, Argentina. Giornale Italiano di Entomologia 9: 1-2.

Duffy, E.A.J. 1953. A monograph of the immature stages of British and imported timber beetles. London, British Museum (Natural History), 350p.

. 1960. A monograph of the immature stages of Neotropical timber beetles (Cerambycidae). London, British Museum (Natural History), 327p.

Gilbert, F.S. 1985. Diurnal activity patterns in hoverflies (Diptera, Syrphidae). Ecological Entomology, London, 10: 385-392.

Hatschbach, G. \& H. Moreira Filho. 1972. Catálogo florístico do Parque Estadual de Vila Velha (Estado do Paraná - Brasil). Boletim da Universidade Federal do Paraná, Série Botânica, Curitiba, 28: 1-54.

IBGE (Instituto Brasileiro de Geografia e Estatística). 1992. Manual técnico da vegetação brasileira. Rio de Janeiro, IBEGE, Séries Manuais Técnicos em Geociências 1, 92p.

IsHIHARA. M. 1998. Geographical variation in insect developmental period: effect of host plant phenology on the life cycle of the bruchid seed feeder Kytorhinus sharpianus. Entomologia Experimentalis et Applicata, Dordrecht, 87: 311-319.

Linsley, E.G. 1961. The Cerambycidae of North America. Part 1. Introduction. University of California Publications in Entomology, Berkeley, 18: 1-135.

Lorenzi, H. 1992. Árvores brasileiras. São Paulo, Editora Plantarum Ltda, Nova Odessa, vol. 1, 384p.

. 1998. Árvores brasileiras. São Paulo, Editora Plantarum Ltda, Nova Odessa, vol. 2, 352p.

MAACK, R. 1981. Geografia Física do Estado do Paraná. Rio de Janeiro, José Olympio Editora, 450p.

Maier, C.T. \& G.P. Waldbauer. 1979. Diurnal activity patterns of flower flies (Diptera: Syprhidae). Annals of the Entomological Society of America, College Park, 72: 5561.

Revista Brasileira de Zoologia 20 (1): 141 - 152, março de 2003 
Marinoni L. \& S.R. BonatTo. 2002. Sazonalidade de três espécies de Syrphidae (Insecta, Diptera) capturadas com armadilha Malaise no Estado do Paraná, Brasil. Revista Brasileira de Zoologia, Curitiba, 19 (1): 95-104.

MARINONI, R.C. 1969. Sobre a biologia e ontogenia de Oncideres dejeanii Thompson, 1868 (Coleoptera-Cerambycidae). Boletim da Universidade Federal do Paraná, Série Zoologia, Curitiba, 3 (8):193-201.

Marinoni, R.C. \& R.R.C. Dutra. 1993. Levantamento da fauna entomológica no Estado do Paraná. I. Introdução. Situações climática e florística de oito pontos de coleta. Dados faunísticos de agosto de 1986 a julho de 1987. Revista Brasileira de Zoologia, Curitiba, 8: 31-73 [1991].

Marinoni, R.C.; N.G. Ganho \& C.S. Ribeiro-Costa. 2002. Feeding habits of Nyssodrysina lignaria (Bates) (Coleoptera: Cerambycidae: Lamiinae). Proceedings of the Entomological Society of Washington 104: 817-819.

Marinoni, R.C.; N.G. Ganho; M.L. Monné \& J.R.M. Mermudes. 2001. Hábitos alimentares em Coleoptera (Insecta). Ribeirão Preto, Holos Ed., 63p.

Martins, U. 1971. Monografia da tribo Ibidionini (Coleoptera, Cerambycidae). Distribuição geográfica. Arquivos de Zoologia, São Paulo, 16 (6): 1343-1508.

Matsumoto, K.; S.B. Irianto-Ragil \& H. Kitajima. 2000. Biology of the japanese green-lined albizzia longicorn, Xystrocera globosa (Coleoptera: Cerambycidae). Entomological Science 3 (1): 33-42. Resumo disponível no Biological Abstract, acessado em 20 de julho de 2001.

Monné, M.A. 1995. Catalogue of the Cerambycidae (Coleoptera) of the Western Hemisphere. São Paulo, Sociedade Brasileira de Entomologia, 196p.

Milano, M.S.; M.M. Brassiolo \& R.V. Soares. 1987. Zoneamento ecológico experimental do Estado do Paraná, segundo o sistema de zonas de vida de Holdridge. Floresta, Curitiba, 17
(1/2): 65-72.

NAPP, D.S. 1976. Revisão dos gêneros Compsocerus Lepeletier \& Serville, 1830 e Paromoeocerus Gounelle, 1910 (Coleoptera, Cerambycidae). Revista Brasileira de Entomologia, São Paulo, 20 (1): 1-64.

. 1977. Revisão do gênero Unxia Thompson, 1860 (Coleoptera, Cerambycidae). Revista Brasileira de Entomologia, São Paulo, 20 (3/4): 117-152.

ODum, E.P. 1988. Ecologia. Rio de Janeiro, Editora GuanabaraKoogan, 434p.

PIANKA, E.R. 1966. Latitudinal gradients in species diversity: a review of concepts. The American Naturalist, Chicago, 100 (910): 33-47.

Rohlf, F.J. 1994. NTSYS-pc. Numerical Taxonomy and Multivariate Analysis System (version 1.80). New York, Exeter Software, 187p.

Rosenzweig, M.L. 1995. Species diversity in space and time. Cambridge University Press, Cambridge, p. 68-72.

SAMWAYs, M.J. 1995. Insect Conservation Biology. London, Chapman \& Hall, 358p.

Southgate, B.J. 1981. Univoltine and multivoltine cycles. In: V. LABEYRIE (Ed.). The ecology of bruchids attacking legumes (pulses). Dordrecht, Kluwer Academic Publishers Group, $213 p$.

Veloso, H.P. \& L. Góes Filho. 1982. Fitogeografia Brasileira. Classificação fisionômica-ecológica da vegetação neotropical. Boletim Técnico Projeto RADAMBRASIL, Série Vegetação, $85 \mathrm{p}$.

Wolda, H. 1998. Insect seasonality: Why? Annual Review of Ecology and Systematic, Palo Alto, 19: 1-8.

ZaJciw, D. 1958. Fauna do Distrito Federal XLVIII. Contribuição para o estudo dos longicórneos do Rio de Janeiro (Coleoptera, Cerambycidae). Boletim do Museu Nacional, Zoologia, Rio de Janeiro, (189): 1-26.

Recebido em 25.XI.2002; aceito em 14.III.2003. 